\title{
O MUNDO DO JOVEM: ADOLESCÊNCIA EM OITO REGIÕES DO GLOBO. ADOLESCÊNCIA NA ÁFRICA SUB-SAARIANA
}

\section{THE WORLDS'S YOUTH: ADOLESCENCE IN EIGHT REGIONS OF THE WORLD. ADOLESCENCE IN SUB-SAHARAN AFRICA}

\begin{abstract}
Elaine Pedreira Rabinovich ${ }^{1}$
NSAMENANG, A. Bame. Adolescence in Sub-Saharan Africa: An image constructed from Africa's triple inheritance. (pp. 61-104). In B. Bradford BROWN, Reed W. LAWSON \& T. S. SARASWATHI (Eds.). The worlds's youth: Adolescence in eight regions of the globe. Cambridge: Cambridge University Press, 2002. 376 pp; Hardback, ISBN 052180910X, c. 50.00 libras; Paperback, ISBN 0521006058, c. 18.95 libras. (www.cambridge.org).
\end{abstract}

Este livro é o resultado de um projeto ${ }^{2}$ realizado pelo Grupo de Estudo sobre a Adolescência no século XXI que encomendou a estudiosos de várias partes do mundo dois conjuntos de trabalhos para dar suporte às suas discussões sobre o possível cenário dos adolescentes nos anos 2030-2050. Para este volume, foi pedido a estudiosos de uma particular nação ou região do mundo que descrevessem as condições atuais e as possibilidades futuras para os adolescentes na nação ou região. No outro conjunto de escritos, publicados como um volume separado (MORTINER \& LAWSON, 2002), foi pedido que os autores abordassem as instituições externas e as mudanças que afetam os adolescentes. Baseados nestes dois volumes, o grupo de estudo preparou um terceiro volume que lida com a influência das mudanças societárias na competência e bem-estar dos adolescentes (LARSON, BROWN \& MORTINER, 2002).
Neste livro, estudiosos de oito regiões do mundo - África, Índia, China e Japão, Sudeste da Ásia, Sociedades árabes, Rússia, América Latina, Países Ocidentais - examinam a preparação dos jovens em quatro áreas: relações interpessoais, na família e com amigos; preparação para o trabalho; saúde física e mental, e comprometimento cívico. Os artigos, baseados em pesquisas, avaliam como a globalização, as mudanças demográficas, as políticas sociais, e inúmeros outros fatores estão alterando as experiências dos adolescentes. O objetivo foi verificar em que extensão a adolescência é um estágio de vida nas várias sociedades e examinar como este período é experienciado em cada região.

Das oito regiões escolhemos, em um primeiro momento, o capítulo que versa sobre a África, de autoria de A. Bame NSAMENANG, intitulado: Adolescência na África Sub-Saariana: uma imagem construída da tríplice he-

1 Psicóloga, membro do CDH-FSP/USP e do LAPSI-IPUSP, editora-assistente da RBCDH, Doutora em Psicologia Social - IPUSP, tem se dedicado a estudos intra-culturais na sociedade brasileira, enfocados do ponto de vista do desenvolvimento humano e centrados no contexto onde o desenvolvimento ocorre.

2 O grupo de estudos foi coordenado por Reed W. LAWSON, com a colaboração de Jeylan T. MORTIMER e B. Bradford. BROWN. Apoios: Society for Research on Adolescence, International Society for the Study of Behavioral Development, W.T. Grant Foundation, Johann Jacobs Foundation, W.K. Kellogg Foundation. 
rança africana. O Prof. Dr. A. Bame NSAMENANG, da Universidade de Yaounde e do Centro de Recursos ao Desenvolvimento Humano, Bamenda, Cameroon, África, tem se notabilizado por descrever e articular teoricamente o desenvolvimento de crianças e adolescentes africanos.

$\mathrm{O}$ autor inicia apontando que a psicologia do adolescente tem sido um empreendimento eurocêntrico e, freqüentemente, etnocêntrico, onde os pesquisadores não desenvolveram a consciência de que o estudo em outra região cultural poderia levar a resultados diferentes. Propõe, em oposição ao foco teórico de uma perspectiva mais individualista que domina os paradigmas ocidentais, a caracterização da ontogenia social africana como um processo cumulativo de integração social na família e na sociedade. Espera, com isto, levar os cientistas ocidentais a questionar criticamente os seus motivos para desconsiderar as psicologias não ocidentais sobre a adolescência, como a do Sub-Sahara.

O processo de aculturação e globalização tem dado à África contemporânea um sistema de tradições antigas indígenas e legados importados que modelam a experiência e produzem imagens dos e para os adolescentes. Forças e imagens indígenas e estrangeiras coexistem nas mesmas comunidades e indivíduos, produzindo a tripla herança: influências islâmicas, ocidentais e tradicionais, complicando a adolescência, complicação esta que deve ser levada em conta no seu estudo.

O autor apresenta, a seguir, o cenário tradicional e discute aspectos de sua realidade atual. Na visão de mundo africana tradicional, a criança é um agente ativo que se desenvolve em um campo sociocultural no qual a plenitude da pessoa é adquirida em degraus durante a ontogenia; tornar-se um adulto é um processo gradual de incremento maturacional. Deste modo, a adolescência não é um estágio ambíguo mas uma passagem entre os estágios de aprendizagem social da infância e a plena integração social da vida adulta. $\mathrm{O}$ autor utiliza uma metáfora para exprimir tal processo ontogenéti-co gradual: a da semente, nutrida e cuidada até a maturidade em um jardim sociológico. A fase mais formal desta socialização ocorre durante a celebração ritual da puberdade sendo que, anteriormente, cultivou-se um caráter virtuoso e os valores de cooperação e generosidade. O estágio adulto não é atingido automaticamente mas apenas quando "casado com filhos". Contudo, o autor sinaliza que a socialização dos jovens africanos está sendo modificada pelas conseqüências de escolarização e das exigências da urbanização e da comercialização.

Tal desenvolvimento tem o seu locus na família e nos amigos. A família na África é formada por pessoas ligadas por sangue, casamento, adoção por instrumentos psicossociais, culturais e econômicos de adaptação compartilhadas. Nela, o autor destaca as expectativas parentais como os norteadores do desenvolvimento, e a polimorfia da família que permite incorporar pessoas, crianças e adolescentes. Aponta o autoritarismo como algo consentido pelos jovens, mas tal autoridade, assim como inúmeros outros aspectos, está em competição com a modernidade e a globalização.

Discute a importância do grupo de coetâneos, da sexualidade e da saúde reprodutiva, sendo que o sexo pré-marital é tradicionalmente proscrito. Aponta que a transmissão e orientação dos comportamentos sexuais aceitáveis pelos avós, pela tradição oral, parecem estar perdendo sua relevância rapidamente.

No tópico educação, o autor declara que vai propositadamente focalizar os esforços indígenas educacionais pois, enquanto nas tradições familiares africanas as crianças são encorajadas a observar e participar das atividades culturais e econômicas que enfatizam normas socialmente distribuídas, o papel da escola formal é ajudar os africanos a sobrepujar as suas deficiências culturais. A escola visa a “domesticação da mente selvagem”, não incluindo e incorporando o pensamento original africano, o que acaba minando-o. 
Quanto ao ingresso no mundo econômico, os adolescentes africanos não encontram empregos nem um modo de inclusão econômica significativa em suas comunidades, o que está sendo visto como um índice de exclusão e marginalização progressivas. Deste modo, embora o ensino tradicional não capacite o jovem a enfrentar a globalização, ao menos, este subsiste com as suas capacidades autóctones, enquanto o ensino formal cria jovens desempregados e totalmente dependentes de seus pais. A proibição de trabalho infantil - um modo tradicional de cada membro contribuir, segundo a sua capacidade, ao bem-estar familiar - pelas agências internacionais, condenou milhares de jovens à inatividade, em vez de criar mais trabalho.

Além do exposto anteriormente, para o autor, as necessidades do jovem sub-saariano podem estar comprometidas por: 1 . uma rede social densa; 2 . doenças endêmicas e problemas de saúde freqüentes; 3. episódios recorrentes de fome e mesmo de inanição; 4 . guerras e conflitos armados; 5 . baixa expectativa de vida e freqüentes experiências de perdas; e 6. conflitos emanando dos imperativos indígenas e realidades importadas. Estes e outros indicadores frustram os esforços dos jovens, não sendo geralmente considerados pelos pesquisadores ocidentais.

Conclui apontando, basicamente, para dois pontos importantes: o primeiro é não opor tradicionalismo à modernidade porque, assim fazendo, estaremos pressupondo uma incompatibilidade inerente a eles e impondo uma interpretação unilinear, externalizada, sobre a cultura indígena. Enfatiza a inclusão dos ado- lescentes na agenda de pesquisa sobre eles como criadores e conhecedores de significado e que os data sobre adolescentes diferem dos dados dos adolescentes; o segundo ponto: a necessidade de um manejo competente dos desafios e expectativas do terceiro milênio pelos jovens africanos, que necessitam, para isto, ser ajudados focando-se as realidades locais na medida que são confrontadas com os imperativos da globalização. Para ele, o desafio mais urgente é criar oportunidades para os jovens aprenderem a desenvolver e maximizar os seus potenciais, sendo a chave para esta inclusão social a participação, o diálogo respeitoso e a comunicação.

Na inevitável comparação com a realidade brasileira, emergem inúmeros pontos de semelhanças, assim como algumas diferenças. Contudo, essa proximidade não encontra respaldo na literatura citada, onde apenas Barbara Freitag comparece, predominando autores americanos e europeus para sustentar e dar credibilidade à sua fala. Isso mostra como uma cultura secular como a africana precisa se justificar baseada em "autoridades" a ela externas. Há alguns anos em um congresso da ISSBD, Bame expressou a imensa dificuldade que é transpor a sua realidade de uma língua a outra e adequála aos padrões ocidentais da comunidade científica. Neste texto, ele se revela um autor maduro que se sobrepõe à dificuldade acima apontada, mostrando um pensamento autônomo e pleno de respeito à sua origem africana. Nós, brasileiros, ampliamos a nossa consciência crítica a respeito de nossa identidade cultural a partir de um texto tão rico, profundo, intenso e extenso como este.

\section{REFERÊNCIAS BIBLIOGRÁFICAS}

LARSON, Reed B.; BROWN, B. Bradford; MORTINER, Jeylan T. (Eds.). Adolescents'preparation for the future: Perils and promise. New York: Blackwell, 2002.
MORTINER, Jeylan T.; LARSON, Reed B. (Eds.). The changing adolescent experience: Societal trends and the transition to adulthood. New York: Cambridge University Press, 2002. 